\title{
4 The Social Movement Scene of Health
}

\begin{abstract}
Chapter 4 delves into the analysis of the social movement scene of health, by focusing on the advent of social clinics and the provision of primary healthcare services free of charge. The exclusion of almost one third of the Greek population from the health system triggered the expansion of social clinics across the country and granted them a contentious role. By paying attention to the clinics' organizational structure and decision-making systems, resources and identity, the chapter explores the contentious mechanisms that shaped the rise of the clinics, their coordination and the solidarity network of drugs distribution. At the same time, the analysis of the boundary enlargement process touches upon the clinics' relations with state and municipal authorities.
\end{abstract}

Keywords: Health movements; Social clinics; Solidarity pharmacies; Free healthcare

The social movement scene of health comprises another example which emerged due to the recent economic crisis and the conditions of austerity. Compared to the plurality of the repertoires analysed in the previous chapter, the health scene focuses on the advent of social clinics and the provision of primary healthcare services and medication free of charge. This chapter aims to investigate the social movement scene in the health sector, in order to unravel the development of the boundary enlargement process. By paying attention to the clinics' organizational structure and decision-making systems, resources and identity, we explore the basic mechanisms and sub-mechanisms that shaped the rise of the clinics, their coordination and the construction of an unofficial solidarity network of drugs distribution, as well as their relationship with the state and municipal authorities.

Malamidis, Haris, Social Movements and Solidarity Structures in Crisis-Ridden Greece. Amsterdam, Amsterdam University Press 2021 DOI: $10.5117 / 9789463722438 / \mathrm{CHO} 4$ 


\subsection{Organizational Structure}

\subsubsection{Affinity Groups Modeling and the Coordination of Autonomy}

As stated above, social clinics are voluntary organizations offering free of charge healthcare services and medicine to people in need, situated within the broader anti-austerity campaign. These two characteristics reveal the two axes on which the clinics lie, namely the operational and political. As in pretty much every organized collective belonging to the broader social movement community, these two aspects are inextricably linked. These are also central accounts of the pre-figurative politics approach, meaning that the organizational and operational aspects of an organization reflect its political ambitions for a future society. In the following text we try to mark the different tasks these axes contain, in order to reveal the clinics' peculiar characteristics that take place due to the process of boundary enlargement.

In terms of the operational characteristics, the literature on social movements refers to the franchise organization type in order to emphasize the 'commonly recognized name and symbol, articulation between organizational levels, locus of member loyalty, territorial hegemony, locus and scope of control over financial affairs, the selection of goals, tactics, and operating procedures, and core technologies' (Davis et al., 2005, p. 191). Despite the provision of the same services, their similar organizational structure and the context of operation which have created a sense of a common identity, social clinics do not constitute a unified body. Rather, they are formed as independent and autonomous entities, which collaborate with each other and develop independent affiliations with official institutional and unofficial movement actors, based on their geographical position and political orientation. Therefore, a more precise description seems to be the affinity groups of modeling, which 'display a great deal of tactical flexibility but are inherently more difficult to direct and control than more centralized forms of organization' (Goodwin and Jasper, 2015, p. 158).

Apart from illustrating how the clinics are organized, the affinity model presents an analytical usage. Diani (2015) notes that feelings of solidarity and belongingness often address specific organizations and the movements as a whole. However, the author argues that affinity group modeling allows some individuals to be identified with a movement without necessarily being loyal to specific organizations (Ibid, p. 21). We are not sure whether this explanation of affinity group modeling corresponds to social clinics, since their members identify with their individual organizations and the 
movement as a whole. In this respect, the clinics' model of coordination takes a dynamic format. Speaking of modes of coordination, Diani and Mische $(2015$, pp. $312-315)$ note that the social movement type of coordination is subject to intense boundary definition and resource allocation, coalitional mode enables intense resource exchanges among the participants but has a limited role in terms of boundary definition, while both resource allocation and boundary definition are rather limited regarding the organizational mode of coordination. However, the authors claim that these are ideal types, since in reality one mode of coordination may include characteristics of the others. As we explore further on, the majority of the social clinics started as independent entities, identified themselves as part of a broader network in the health scene and enabled the exchange of resources, while the internal debates sparked after the "backflip" of SYRIZA, Synaspismos Rizospastikis Aristeras (Coalition of Radical Left) in 2015 shifted the social movement mode of coordination to a coalitional and organizational type.

Among the various models of the different networks participated in the Global Justice Movement (GJM) (Della Porta et al., 20o6, pp. 4957 ), the affinity model, which was popular among the anarchist and anti-authoritarian blocks, has enabled the quick spread of practices. The participation of Greek anarchist and left-wing organizations in these summits and the interaction with foreign groups based on this type of organization led to a diffusion process of the affinity group modeling (Kotronaki, 2015). Affinity group modeling allows the process of diffusion to take place. However, what interests us here, in terms of the boundary enlargement process, are the factors that enable the diffusion to take place. We find the answer in the mechanism of in-group brokerage. In-group brokerage is defined as the 'connection of factions and groups on each side of an "us-them" boundary, without establishing new connections across the boundary' (Alimi et al., 2015, p. 287). The mechanism of brokerage as defined by Tilly and Tarrow refers to 'the production of a new connection between previously unconnected sites' (2015, p. 31). As the creation of new ties among actors is a central mechanism in the overall process of mobilization, brokerage is often taken for granted, without due explanation. In an effort to overcome this obstacle, we explicitly refer to in-group brokerage, where new ties enable the connection of specific actors on the same side of a boundary. This mechanism is tightly connected to the formation of new categories, which, in our case, are visible in the example of social clinics.

Common or similar ideological beliefs are often the broker, which enables the affinity groups modeling to take place (Goodwin and Jasper, 2015, p. 158). 
These are often complemented by moral shocks (Jasper and Poulsen, 1995) and participation in eventful protests (Della Porta, 2008; Della Porta et al., 2018, pp. 1-24). This was the case, for instance, with the riots which followed the murder of Grigoropoulos by the police in Athens city centre in December 2008, which led activists from various ideological backgrounds to squat public buildings and transform them into centres of struggle for the coordination of their actions. In spite of these factors, our research argues that common goals translated into repertoires might also enable the construction of affinity groups modeling. In the case of social clinics, the provision of healthcare services, combined with their autonomy, did not prevent them from establishing a network in order to firstly share and distribute medicine, and secondly to coordinate protests, meetings and produce common denouncements. How have these networks been constructed? The sub-mechanisms of network cultivation and the attribution of similarity seem to provide us with an answer.

Attribution of similarity is defined as 'the mutual identification of actors in different sites as being sufficiently similar to justify common action' (McAdam et al., 2001, p. 334). Scholars emphasize the attribution of similarity as the activator of diffusion, brokerage and scale shift mechanisms (McAdam et al., 2001, p. 335; Tilly and Tarrow, 2015, p. 126). With regards to the social movement scene of health, attribution of similarity among healthcare professionals motivated a number of doctors to engage with the operation of social clinics. The participation of doctors and trainees in the first social clinic in Chania in 1990 enabled the cultivation of a network among the participants. Former trainees of the clinic were among the founders of the social clinics in Rethimno and Thessaloniki. Once the consequences of austerity actualized in the health sector, the members of the Rethimnian clinic started to use their professional networks and contact colleagues in other major Greek cities, in order to create a national mailing list which facilitated the distribution of medicine (Int.1). The attribution of similarity in terms of profession was the mediating factor that helped the establishment of that first network, which consequently started a process of the social clinics' network cultivation. ${ }^{1}$

1 The sub-mechanism of network cultivation has many similarities with what Wang et al. (2018, p. 178) call boundary-spanning, since it fosters inter-organizational ties, enables activists' recruitment and encourages the accumulation of resources. Nevertheless, we think that network cultivation is more appropriate here, since boundary-spanning does not have clear effects in attracting public attention, as well as it describes a larger process compared to the more limited character of network cultivation. 


\subsubsection{Internal Structure}

As autonomous entities, the social clinics decide what kind of organizational structure and decision-making system to follow. Born out of collective actions, they are mostly organized on the basis of a general assembly. The general assembly constitutes the ultimate decision-making instrument and determines the political, social and operational characteristics of each clinic. Procedures within the assemblies of the clinics emphasize their direct-democratic and horizontal character.

Depending on the number of members and beneficiaries, social clinics might also have a coordinating committee which decides its regular operational aspects. A great example here is the Metropolitan Community Clinic at Helliniko (MKIE), among the largest in the country, which, in order to better serve its needs, established a coordinating committee. This functions on an annual base and consists of representatives of the different teams that operate in the clinic. Nevertheless, we should note that despite efforts to appoint new members, the clinic in Helliniko follows an informal tradition of appointing the founding members in its coordinating committee (Int.8). The clinic's founding conditions might also be subject to the organizational principals of the team that established it. The social clinic in Thermi is a suitable example.

Located in the suburbs of Thessaloniki, the clinic in Thermi was established in 2013, following a public call issued by the grassroots citizens' initiative operating in the area. Among the various neighbourhood assemblies that emerged through the decentralization process of the square movement, Thermi citizens' initiative was established in the Fall of 2011, in order to oppose the "haratsi" ad-hoc taxation imposed on electricity bills (CI Thermi, 2013). Together with the incorporation of other practices in the initiative's repertoires of action, the organization of markets without middlemen required the creation of a committee in order to facilitate its operation. Once the idea of establishing a clinic had been put forward, the same committee was in charge of its maintenance (Int.7).

The general assemblies are central to the operation of social clinics. Nonetheless, they are not the only crucial element, since the clinics' organizational structure enables the creation of different groups within their structures. Here, one can find two broad categories of groups that schematically surround the general assembly. The first category includes the groups that have been formed mostly according to the clinics' operational needs, but also help indirectly to achieve their political goals. These groups, like the reception team, the cleaning team, the organization or resources team, have quite clear 
tasks. The MKIE clinic in Helliniko is probably among the ones with the richest organizational structure, since it set up its own press office and radio show, preoccupied with the promotion of the clinic's activities, producing denunciations against austerity in the health sector and publishing cases of patients' maltreatment in public hospitals. Another example is the clinic's welcoming team, which is the first to contact the potential patient and explain the political role of the clinic as well as its conditions and criteria, thus promoting the clinic's political views. As a clinic's representative stressed

the social clinics struggle on two levels. The first level has to do with the demonstration of the patients' problems [...] and the second one has to do with the provision of help by any means. If we erase the one level, on the one hand we would substitute the state, and, on the other hand, we would simply yell (meaning protesting without achieving an outcome). (Omniatv, 2014: 1:02:45-1:03:06 minute).

Additionally, the second category consists of groups which are organized according to the interests of the clinics' members and lie within the boundaries of their operational and political axes. An important example is the clinic in Thessaloniki and the groups of diabetes and "other medicine". ${ }^{2}$ These groups were formed on the side of the clinic's proper operation and deal with the further exploration of the way that medicine is being provided, challenging at the same time the normative doctor-patient relationship (SSCP Thessaloniki, 2015). Not only did social clinics oppose austerity in the heath sector, but they also raised criticism against the mainstream provision of healthcare as another source of inequality.

So far, we have seen that social clinics have followed a structure which has enabled the formation of new groups, both in terms of tasks and of interest. Consequently, this internal grouping enabled the further elaboration of the clinics' members on the principle of self-management. An interviewee argued that,

the connection between the social clinic in Thessaloniki and Vio.Me (occupied factory) was achieved in practice since they participated

2 The clinic's official declaration refers to "alternative medicine" and not "other medicine". However, alternative medicine usually implies alternative medical practices such as acupuncture, homeopathy, etc. and does not seem to correspond to the work of the group. Therefore, after communicating with the clinics' members, we agreed on the term "other medicine", which is the literal translation of $\alpha \lambda \eta \iota \alpha \rho\left\llcorner x \eta^{\prime}\right.$ team. 
in common struggles. The clinic provided its services to the workers of Vio.Me, and Vio.Me provided its products to the clinic which were subsequently distributed to its beneficiaries. But the real connection was achieved once we recognized our common views on autonomy, self-management, and direct democracy and, at the same time, our will to seek a different content. In particular, when Vio.Me asked itself "what am I producing?" and the clinic asked itself "what healthcare do I provide?”. (Int.3)

Social movement scholarship suggests that cross-movement boundaryspanning bears the potential to gain new support for a social movement, but at the same time runs the risk of becoming more vulnerable in terms of its identities and goals (Wang et al., 2018, pp. 179-180). Nevertheless, it was due to this attribution of similarity that the workers of Vio.Me and the members of Thessaloniki social clinic's "other medicine" group proceeded with the establishment of the Workers' Medical Centre in the factory of Vio.Me $\mathrm{Me}^{3}$ in the Fall of 2015, which specifically aimed in experimenting with a holistic approach to medicine. On a similar ground, the clinic in Thessaloniki was connected both with the movement against the privatization of the water company and the movement against the gold-mining operation in the nearby area of Chalkidiki. As an interviewee claims, 'the health movement can connect with every movement, since the issue of health is rather wide and the harmful factors too many' (Int.4). In order to better explain the crucial role of these mechanisms, we should dig deeper into the structure of the clinics and turn our attention towards other aspects of their organization.

\subsubsection{Core and Peripheral Networks}

The social clinics operate on a voluntary basis. ${ }^{4}$ Volunteers can be divided into specialized members (doctors, pharmacists, dentists and other healthcare practitioners) and non-specialized members (people in solidarity who are employed either as doctors' assistants or in every other bureaucratic

3 This clinic is an autonomous entity which was born after the cooperation of the "other medicine" group of Thessaloniki's social clinic with the workers of Vio.Me.

4 In earlier chapters we argued that social clinics distinguish themselves from charity organizations. In this regard, they often avoid the term volunteer, since it denotes actions of charity and, therefore, excludes their political characteristics. However, it was also quite often the case that both during the document analysis and interviews, social clinics have used the term volunteer to refer to their members. Thus, in this paper we refer to the members of the clinics by using the terms "volunteers", "members", "participants" and "activists" interchangeably. 
task like the secretary). Social movement scholars argue that although the labour movement had its social basis on the working class, the anti-austerity mobilizations were constituted by the precariat (Della Porta, 2015). Can we say the same for the organizations that participated in these mobilizations? Although this argument can be applied mostly in relation to the organizations that operate within the social movement scenes of food and labour, the social movement scene of health presents a slightly different story.

Despite the lack of a comprehensive socio-demographic study on the members of the clinics, our empirical research argues that the clinics' specialized personnel often consist of healthcare professionals who already have an occupation, something that is quite relevant to the development of the clinics for two reasons. First, the fact of having an established professional relationship with other doctors working in private offices and public hospitals helped the growth of the clinics; second, the requirement of professionalized personnel not in the clinics' periphery, as is usually the case with advocates and lawyers participating in other social movement organizations (SMOs), but in the core of their operation, has enabled the elaboration of previously unconnected individuals with collective action, based on their profession. In this regard, the attribution of similarities among healthcare professionals becomes a nodal point in the clinics' development. The clinics' external networks also point us towards this direction.

Apart from the core group that facilitates the clinics' operation within their premises, in most cases there are also two external networks of doctors which ease the clinics' operation. Based on professional relationships with their colleagues in social clinics, many doctors working in the private sector agreed to provide their services to the clinics' beneficiaries free of charge. These range from general doctors and pathologists (general practitioners) to dentists and microbiologists. In some cases, like in the clinic in Thermi, where there are no qualified doctors amongst the founding members, the entire operation relies on this external network.

The second external network is made up of doctors working in the public sector. Some of these networks have been maintained from previous phases of mobilization in the health sector, like the one in Thessaloniki (Int.3). However, in most cases it was the professional ties between the doctors from the clinics and their colleagues from the public hospitals that enabled the development of the network. The immediate outcome was for doctors working in the public sector to admit the clinics' beneficiaries in hospitals for secondary and tertiary treatment free of charge. These services cover specialized examinations as well as surgeries. 
For the construction of these networks, the attribution of similarity in terms of professional networks played a crucial role. As an interviewee from the MKIE clinic notes:

our doctors came in contact with some other doctors out there and they explained our situation. The other doctors replied that they cannot participate in the clinic's offices since they are working in their private ones both in the morning and in the evening. So, 'send them here'. (Int.8)

The clinic in Thermi, of which the founding team did not include healthcare professionals, depicts a clear case in which the attribution of similarity sub-mechanism sets in motion an emulation process, 'as people imitate the performances that early risers have invented' (Tilly and Tarrow, 2015, p. 126). Quoting an interviewee:

in the beginning we prepared a list with all the doctors in Thermi. Our aim was to visit everyone, but we never managed that. We visited an important number of doctors, around $15 \%$ and then it worked alone. Since many doctors' offices are close to each other, same buildings, etc. what functioned was the "references". (Int.7)

In many cases doctors had to disobey the rules in order to admit patients to the hospitals free of charge. However, this does not reduce the efficiency of these networks for the overall operation of the clinics. One interviewee notes that,

one hospital used to help us with mammograms since we knew two persons working in the radiology department. Once, our gynecologist palpated a patient and directed her there. The doctors in the radiology department examined her with a mammogram and they found something. But since it was found in time, the woman didn't need any surgery and it caught it up...Then she came here and you...You turn emotional. (Int.10)

On the same topic, another interviewee added that:

a 28-year-old girl came one month ago (April 2016) to the clinic having a pain in her shoulder. When I looked at the actinography, I was shocked. [...] She was 28 years old and seven months earlier she had miscarried. She went to Papageorgiou hospital and she was told that if you do not run you will lose your arm. This is tragic. That girl was a second-generation 
migrant, speaking Greek fluently and obviously she was uninsured. Together with other people in solidarity we tried to give her admission to the hospital. That (illness) was so aggressive that the two months she lost with going to the hospitals without even giving her an actinography were decisive. They gave her painkillers and kicked her out. She could not only lose her arm but die. Due to our intervention, this moment she is in Theagenio hospital doing chemotherapies. (Int.6)

The attribution of similarity in terms of profession seems to be important for another reason. Due to the unlikelihood of finding employment elsewhere, it was often the case that many of the clinics' members engaged initially in order to acquire unofficial medical training. An interviewee from Thessaloniki argues that,

I have been invited by a fellow student. He asked me "why don't you come to join us?" Initially, I discerned my personal profit which was the training in the clinic. In the beginning, it was neither the political, nor the ideological reasons. (Int.5)

In some cases, like the clinic in Athens, which has an official legal status, the "trainees" receive also recommendation letters which would facilitate their future employment. However, the absence of this official recommendation letter does not prevent graduate students from volunteering. An interviewee from Peristeri notes that their trainees are 'nurses, psychologists, and doctors. We welcome them. But the problem is that we cannot provide them with any certificate since we do not have a legal form' (Int.11).

The attribution of similarity in terms of professional networks was the sub-mechanism that facilitated the cultivation of a network among the healthcare professionals employed in the clinics. However, the attribution of similarity was also important for the non-specialized personnel. The economic difficulties that led to the loss of insurance coverage did not apply to a specific marginalized group but to broader parts of the Greek society. Our field research, and other empirical inquiries on social clinics (Cabot, 2016, p. 158), note that the threat of becoming a potential beneficiary attributed similarity to the clinics' non-specialized personnel perceived as a moral shock (Jasper and Poulsen, 1995) and enabled their engagement. In this regard, a non-specialized interviewee responded:

Last week I watched "I, Daniel Blake" and everyone found it a striking film. Indeed, it would be quite striking if I hadn't experienced similar instances 
in the clinic over the last three years. It is quite different to see that your fellow citizen, who lives ten blocks further, has similar problems. (Int.11)

Research on social movements has shown that objective or relative deprivation theories as well as grievance theories have little to say about the individuals' participation in collective action, unless they are combined with other factors. In line with this criticism, the attribution of similarity should also take into account the political axe of social clinics. 'The activity of the clinic and the needs of the Greek society were the reasons that attracted me', were the words of an interviewee, who added that,

the collective decision-making, and the respect to the others' opinion were the aspects of democracy as we experienced it in the Syntagma square movement and we transferred them in the clinic. [...] This was the spirit of the Syntagma square, meaning the direct, unmediated communication, equal cooperation and mutual respect. (Int.8)

This process of diffusion, through which elements of the square movement have been transferred to the clinics, has also occurred in other cases, without having a direct link between the movement and the clinic's founders. The participation of 'society's anthropogeography' (Int.11), that an interviewee from Peristeri described as the members' ideological pluralism, has been filtered through a minimum political agreement regarding the clinic's operation. The understanding that everyone's faith is in a common mission despite their individual political orientation, was an essential element for cultivating the clinics' network and thus merging the operational axis with the political one. This is clearly reflected in the words of an interviewee who argues that,

it is quite characteristic that once you join the clinic you have only one identity; you are a member of the clinic. Whether you are a nuclear scientist, cleaner or painter, member of a party, independent or anarchist, once you join the clinic you have one identity. And this is the connective element. You provide a service and you decide on this. Beyond that, any thing you do outside of the clinic, it is your business. (Int.8)

\subsection{Resources}

Resources reflect the process of boundary enlargement in two ways. First, being a crucial aspect of SMOs' operation, the factor of resources enabled 
the activation of the out-group brokerage mechanism, an important component in the overall process of boundary enlargement. However, resources should not just be seen as a factor where mechanisms are being activated; they should also be understood as an analytical category per se. The classic approach to resources underlines their utility to serve the survival needs of SMOs. During times of austerity this seems to change. In particular, the previous pragmatic understanding is re-interpreted with resources perceived as a means of solidarity, which strengthens the ties between different components of the social movement community. In order to further explore this double character, in respect to the health social movement scene, we now turn our focus to the role of resources in the operation of social clinics and their three large categories, namely fixed costs, such as rent and bills; office and medical equipment; and medicine.

\subsubsection{Fixed Costs}

The Carta of Social Solidarity Clinics and Pharmacies, a collective declaration signed by the majority of social clinics regarding the terms of their operation, clearly states that social clinics 'are based on citizens' solidarity and they do not have any economic dependence on official, state and European institutions. [...] They receive contributions, donations and grants of any kind that are needed but they advertise neither individual nor collective donors', while 'they do not allow the involvement of any party in their operation' $\left(\mathrm{S}_{4} \mathrm{~A}, 2013\right)$. Although this declaration applies to the clinics' independence in terms of their decision-making procedures as analysed in the previous section, the same cannot be said regarding their resources.

The vast majority - 45 out of 56 - of healthcare providers born during the crisis (including both movement-oriented and institutional social clinics) are placed in spaces which have been granted by another actor, while only eight clinics operate on rent premises (Adam and Teloni, 2015). With regards to the first category, 25 of them have been granted a place by municipal authorities, while the rest of the contributors are distributed among the church, labour centres, individuals in solidarity, hospitals, universities and other institutional actors. Surprisingly, the organizations of the second category fund their rental expenses mostly with the help of municipal authorities and other institutional actors, while only one clinic pays its own rent (Ibid, pp. 44-47). Unfortunately, Adam and Teloni's (2015) research does not provide further evidence regarding the place of operation of social 
clinics or the sixteen healthcare providers which were not included in the authors' sample. ${ }^{5}$ Moreover, the time span of their inquiry (the research was conducted in 2014) did not take into consideration clinics that were established later on, such as the clinic in Piraeus or the Workers' Medical Centre at Vio.Me factory, which operates in squatted premises. However, these results do witness a clear tendency within social clinics to operate in places that have been granted by institutional actors. A closer look at some specific cases enables us to better understand how this tendency makes up part of the broader process of boundary enlargement and specifically of out-group brokerage and resource certification. Out-group brokerage stands for 'the production of a new connection between previously unconnected or weakly connected sites' (Alimi et al., 2015, p. 287). Here, out-group brokerage refers to the development of ties with individuals but mostly with collective actors and organizations that constitute the broader social movement sector. Additionally, resource certification entails the endorsement of specific activities as described by the mechanism of certification we referred in Chapter 3 (Alimi et al., 2015, p. 287), applied to the aspect of resources.

Many clinics have been granted either a place or payment of their rent by municipal authorities. This was achieved with the use of conventional means, like discussion and cooperation with municipal authorities, as it occurred in the cases of Rethimno (Int.2), Themi (Int.7), MKIE in Helliniko (SSCP MKIE, 2013), Social Clinic in Korydalos (SCK) and Piraeus (Int.9); or through confrontational means, for example the informal threat of squatting the place in the case of Nea Philadelphia (SSCP Nea Philadelphia, n.d.; Int.14). In each of these cases, framed by McAdam et al. as 'social movement repertoire' (2009, p. 262), resources acted as a form of certification, whereby the external authorities signaled and recognized the claims of the clinics (Alimi et al., 2015, p. 287). Despite these clear-cut paths, the clinics also managed to gain legitimacy through resources by other means. Following Tilly and Tarrow's certification which implies 'an external authority's signal of its readiness to recognize and support the existence and claims of a political actor' (2015, p. 36), we call this resource certification.

In Chapter 2 we outlined the conflicts between movements and trade unions and formal labour associations. However, the internal competition of different parties inside the trade unions and the pressure from SYRIZA MPs (Int.4) have opened a niche for Thessaloniki's social clinic. In particular, the clinic was

5 This point refers to six cases in which the researchers did not manage to contact with the clinics' representatives and ten cases in which the clinics denied their engagement in the exercise (Adam and Teloni, 2015, p. 20). 
granted a place through the Institute for Macedonian Studies, an organization which belongs to Thessaloniki's labour centre. This niche has been used by other movement organizations, such as the migrants' school Odysseas ${ }^{6}$, an organization with strong tradition and ties to the city's movement community. Additionally, the role of Solidarity for All (S4A), as described in Chapter 2, appears to be in line with these alternative paths. Despite its party origins, the clinic in Athens funds its rental expenses through the contribution of foreign individuals and collectives in solidarity, after the mediation of $\mathrm{S}_{4} \mathrm{~A}$ (Int.10).

Apart from the location, certification in terms of resources, both by institutional and movement actors, is also expressed in the case of utility costs (such as electricity, water, telephone and others). These are covered either by the municipal authorities, like in the cases of Rethimno (Int.2), MKIE (Int.8), Nea Philadelphia (Int.14), or by donations. This evidence leads us to some conclusions. First, although social clinics are skeptical towards institutional actors, in many cases the same cannot be said with regards to municipal authorities. Second, the coverage of the clinics' fixed costs by institutional or non-institutional actors removed an important burden from their overall costs. Subsequently, the clinics acquire greater flexibility and use their resources for other activities. Third, the use of resources in terms of the fixed costs reveals a mechanism of certification by institutional actors. However, this recognition applies also to individuals and organizations in solidarity with the clinics, and acts as a connective factor with the broader social movement community. This can be better observed, once we shift our focus to medical and office equipment and medicine.

\subsubsection{Medical and Office Equipment}

Earlier we pointed out how municipal authorities became engaged in the clinics' resources. Although there are no similar trends in terms of equipment and medicine, both aspects present another set of dilemmas. Donations are the basic source of funding for clinics to acquire office and medical equipment. These donations, as we explain further on, can be either in-kind or monetary. In the first case, donations in kind were granted by doctors' private offices and hospitals, as well as domestic and foreign individuals and collectives in solidarity. Quoting an interviewee from Peristeri,

we found the furniture by ourselves. Some were destroyed and we fixed them. Some of them came from a shipping company which went bankrupt. 
Some others, like a bookcase, came from a sex shop that ceased operation! We received our medical beds from a hospital which withdrew its equipment. (Int.12)

Although donations in kind were preferred as a transparent method of funding the clinics' activities, it raised concerns as to the donors' "origins". The mediating role of $\mathrm{S}_{4} \mathrm{~A}$ was criticized by many clinics. Once again though, $\mathrm{S}_{4} \mathrm{~A}$ was a valuable actor in terms of donations. As an interviewee (Int.9) explained, the SCK clinic established its dental clinic when $\mathrm{S}_{4} \mathrm{~A}$ communicated that the French metal union would like to fund one. This procedure took place in the aftermath of the $\mathrm{S}_{4} \mathrm{~A}$ campaign abroad and once the organization communicated the potential funding to the mailing list of the clinics, with the SCK expressing its interest. Donations offered by pharmaceutical companies were also controversial. The clinics condemned the deconstruction of the public health system and the outsourcing of the health services to private actors. In this context, pharmaceutical companies were clearly attributed a negative role in transforming medicines from common goods to commercial products. However, the situation was further complicated as the non-advertisement of the donors seemed to balance (and in some cases to overcome) this negative attribution. Thus, the clinic in Athens directly excluded any donations from pharmaceutical companies (Int.10), the one in Thessaloniki was skeptical and sought to further explore the origins of the donors, while the MKIE clinic approved these donations due to the general rule against advertising the donors, arguing nonetheless that almost $90 \%$ of medicine come from individuals in solidarity.

Monetary donations were also a source of controversy. The lack of legal status forced the clinic in Thessaloniki to establish a separate association, specifically for receiving monetary donations. This proved quite helpful since it also guaranteed the clinic's financial transparency. ${ }^{7}$ A process of diffusion took place and other clinics adopted this practice. In some cases, diffusion was achieved through imitation (Campbell, 2005, p. 58) as the popularity of this practice increased. In the case of Rethimno, for example, where one of its doctors studied for her specialization course in Thessaloniki and spent some months in the respective social clinic (Int.1), the diffusion

7 Together with transparency, this practice enables the clinic to identify the source of donations and in some cases, as the ones of the pharmaceutical companies we referred to earlier, to reject them.

8 Campbell's use of imitation is similar with what McAdam et al. (2001) call emulation. Therefore, the two terms are used interchangeably. 
mechanism in establishing a separate association for receiving monetary donations was accomplished due to the in-group brokerage mechanism, as it was described in the previous section.

However, the monetary donations did not find universal application and were rejected by certain clinics. When asked about the procedure in receiving monetary donations, an interviewee from Peristeri replied that the clinic does not receive open donations where one can just donate whatever amount of money they want, but instead, 'we can tell you what our needs are and then you can allocate the respective amount' (Int.11). Although the organization of concerts and fund-raising events in order to pay its bills was included in the clinic's repertoire, the interviewee added that 'we have signed the Charta of social clinics, a clear collective decision, which prevents us from managing monetary donations and advertising the donors' (Int.11). In a similar vein, although slightly diversified, the MKIE clinic rejects monetary donations in order to purposely force potential donors to visit the clinic as a strategy for the latter's mobilization. According to a clinic's representative,

monetary donations force citizens to stay passive. We want them to get mobilized; to buy medicine, bring it to the clinic, have a tour there and mostly to see the patients. Once this procedure is accomplished, that person changes directly; they become our ambassador and transmit our message to society. (Omniatv, 2014, 47:10-48:03 minute)

This logic became quite popular with the square movement and it is largely adopted in the food social movement scene. In these terms, the sub-mechanism of resource certification is interlinked with a strategy of social appropriation, something which is analyzed in detail in the next section. What interests us here, nevertheless, is that the donation of medicine becomes an action that certifies and recognizes the role of the clinics and connects them not only with individuals, but also with collectives in solidarity.

\subsubsection{Drugs and Medication}

Medication and drugs were among the most crucial factors for the development of an in-group brokerage mechanism. The first mailing list, created by the social clinic in Rethimno to facilitate the exchange and distribution of medicine, laid the foundation for the development of the social clinics' network. The role of the first network did not change in the aftermath of SYRIZA's "backflip" and the grievances that the clinics were 
later confronted with. Apart from being an internal broker connecting the clinics, the predominance of medicine among the rest of the clinics' resources seems to be also acknowledged both by the institutional and the non-institutional actors.

Of upmost priority for the pharmacies' operation, the need for the acquisition of drugs and medication led social clinics to form links with previously unconnected sections of the Greek social movement community. Chapter 2 refers to the outcome of the December 2008 riots, the growth of grassroots neighbourhood assemblies and the spread of direct actions. The square movement continued this legacy of pre-figurative politics and expanded it with the organization of collective kitchens and barter networks during the encampments. In the same spirit, social clinics managed to stabilize this tradition and transform the donation of medicine into the practical realization of solidarity.

The premises of many SMOs became collection points for medicine donated to the clinics. Equally frequent was the practice of donating medicine instead of a fee at festivals, concerts, and plays organized by grassroots collectives. According to an interviewee,

every SMO welcomed the clinic. They were collecting medicine during their events. [...] Both the local barter club and the markets without middlemen were always supportive to the clinic and they were collecting medicine during their events and food distribution. [...] I think also the local anti-racist festival was collecting medicine as well. Pretty much in every event organized in Rethimno, among other actions, there were also collecting medicine. (Int.1)

Social movement studies inform us that organizations which focus on broader issues are more likely to form coalitions than those with a narrow focus (Obach, 2004 in Wang et al., 2018, p. 175). Common identities, identity overlap and SMOs affiliation within a specific movement, form an identity aspect that favours the formation of coalitions, while political threats and pre-existing social ties comprise two additional reasons for bringing SMOs closer. It is mentioned above that instead of simply donating medicine, SMOs became collection points to receive medicine for the clinics. This organic connection between clinics and SMOs in terms of the former's operation, acted as a mechanism which certified the clinics' operation based on their resources. SMOs became unofficial brokers between the clinics and the potential donors, in what McCarthy and Zald (1977) would probably call the enlargement of conscience constituents. 
The sub-mechanism of resource certification exceeded the domestic borders. The representative of the MKIE social clinic refers to similar cases where political and social collectives in Greece became focal points for the collection of medicine, while respective collectives in Germany, Italy and France used to collect money to then buy medicine and physically transfer them to the clinic (Litsis and Stefanakos, 2014: 4:00-9:00 minute). Another interviewee argued that the clinic in Thessaloniki 'is among the richest ones, donates money to other clinics and has very good relations with the people in solidarity from abroad' (Int.6), something that led the clinic to establish a reception group in order to communicate with foreign individuals and collectives in solidarity (SSCP Thessaloniki, 2015). With the clinic in Thessaloniki being among the pioneers, these good relations have been attributed by an interviewee to the clinic's novelty but also 'to the fact that we didn't get involved in state's structures', which gifted the clinic 'another level of recognition' (Int.6). This last characteristic is analysed extensively along the chapters of this book but also turns our attention to the political reality of the clinics' first days.

By definition, social clinics promote an anti-racist profile, since they provide healthcare services regardless of racial, ethnic and gender identity. In times when Golden Dawn used to organize blood donations "from Greeks to Greeks" and attempted to infiltrate the national medical associations, the clinics argued that 'doctors cannot be fascists' (SSCP Thessaloniki, 2014c). Apart from making statements, the clinics participated in anti-racist marches and festivals, sent massive solidarity missions to Kombanie and elsewhere (SSCP MKIE 2015e), while the transition from the economic crisis to the refugee "crisis" turned their attention to the provision of services to refugee camps and hotspots across Greece. In this sense, the donation of medicine was pictured as the legitimation of direct solidarity and support to the anti-racist struggle, adding another element that connected the clinics with other forms of the anti-austerity mobilizations.

So far, we have established how resources, and medicine in particular, certified the clinics' operation and caused the connections with SMOs. Nonetheless, Clemens argues that 'protest (and thus SMOs) is an important part of the repertoire of contention [...] but only one part', since 'attention must be paid to other paths of mobilization and levers of power' (Clemens, 2005, p. 364). Therefore, this effort would have been incomplete if we did not take into account the role of medicine certification in respect to institutional actors.

We contacted the local drug stores to collect medicine for the clinic. The flow of medicine started almost the same time we started the provision 
of healthcare services, with medicine arriving here from individuals and pharmacies (Int.7),

stated an interviewee from Thermi's clinic. Other clinics have experienced similar results, with local private pharmacies becoming collection points, where individuals donate medicine (Litsis and Stefanakos, 2014:12:00-15:00 minute). These examples demonstrate a broader network that clinics have developed in order to acquire resources. Nevertheless, they did not limit their role on the demand side of asking for medicine, but they expanded it towards the supply side, by donating medicine themselves. More precisely, it was not rare for clinics to provide their services to beneficiaries that have been directed towards them, by institutional clinics operating by churches and non-governmental organizations (NGOs). Quite striking were the cases in which public hospitals sent their patients to social clinics, since the former were unable to provide treatment (Omniatv, 2014: 15:00-23:00 minute). Apart from treating patients sent by institutional actors, the clinics have also supplied public hospitals and medical centres with medicine and pharmaceutical products (SSCP MKIE, 2012c; 2015b).

The bad conditions of public hospitals have affected their ability to provide medicine for their patients. The clinic has a great stock of medicine. Once we cover our needs and the respective needs of the rest of the social clinics, we donate the remainders to hospitals. [...] Some hospitals ask us indirectly whether we have some specific drugs. However, most often patients receive their treatment in a hospital, and due to the latter's inadequacy to provide them with medicine, the hospital directs the patient here. (Int.8)

As one might expect, this issue raised skepticism and debates within and outside the clinics, regarding their role towards the state and its institutions.

It is a constant dilemma whether our actions transform us into the state's crutch. This is a rather critical question that cannot be answered directly. We are aware of the hospitals' needs and therefore, we provide our services; but at the same time, we denounce the hospitals for not providing medicine to their patients. In simple words, we act by providing our services, but we also reveal that our actions lie in the fact that these despicables don't give money for the patients. That's why this is not mere philanthropy. (Int.8) 
The special weight attributed to denouncements, as a means of justifying the relationship between clinics and state institutions, received great appreciation from other clinics. Specifically, the massive police operations ${ }^{9}$ between 2012 and 2013 in the city centre of Athens led to the imprisonment of numerous undocumented migrants and, among other consequences, the prisoners' medical conditions deteriorated. Confronted with these conditions, members of the clinics experienced what Jasper and Poulsen (1995) call a moral shock. Outraged by the detrimental conditions of deportation centres, some clinics developed relations with the Police Department of Attica's Foreign Administration (PDAFA) by supplying it with medicines and, in some cases examining the prisoners.

The psychotherapist in PDAFA didn't even have an aspirin. We tried to help her through our network. The gravely ill prisoners have been sent to hospitals, issued prescriptions, which were handed to their accompanying policemen, with the latter ones bringing the prescriptions to us. Once, one hospital sent us a prisoner in handcuffs to visit the dentist. [...] Everything was extreme back then. You didn't have an option. Hospitals used to provide the prisoners with two pills only for one day and then issue prescriptions for them to buy the rest. If the prisoner had enough money, the policeman bought the medicine and passed them to them. But there were others who didn't have anything, or the medicine was quite expensive. We were the ones who started supplying them. What should we do? Wasn't that part of our operation? (Int.10)

The clinic in Korinthos employed similar actions in the local prison, while the clinics in Peristeri and SCK did the same in the detention centre of Amigdaleza, Athens. The arrival of the SYRIZA-led governmental coalition in office in January 2015 coincided with the expiration of the contracts of prison doctors, forcing the clinics' staff to pay daily visits to the prisons. 'Especially after January 2015, I went to Petrou Rali (the location of migrants' detention centre) all the time. I was keeping records and issuing denouncements continuously. We didn't simply supply medicine, we impeached everyday' (Int.10). Surprisingly, the interaction of clinics with institutional actors received a quid pro quo form. For example, the public hospital in Rethimno,

9 The name of this operation is actually Zeus Xenios, who according to the Greek mythology was the god that protected strangers and defended hospitality. The use of this code name for arresting and deporting undocumented migrants is another sign that witnesses the brutal anti-migratory political environment of that period. 
offered treatment free of charge for two beneficiaries per day, in exchange for the medicine received by the respective social clinic (Int.2).

The aforementioned narratives demonstrate how the clinics gained legitimacy by public institutions and other formal actors due to their resources. This occurred mostly in times when PASOK, Panellinio Sosialistiko Kinima (Panhellenic Socialist Movement), and ND, Nea Dimokratia (New Democracy) were in government. The arrival of SYRIZA in office reaffirmed and strengthened this recognition. This is made quite clear with the appointment of a founding member of the Rethimno social clinic as the head of the Ministry of Health and the formation of a common working consisted of governmental officials and social clinics' representatives group preoccupied with the introduction of the unemployed in the health system, as we mentioned in Chapter 2. However, certification became even stronger in the summer of 2015, when the refugee flows were combined with the state's inability to cope with the emerging needs.

The instant provision of health services and medicine to Idomeni, Piraeus port and the Aegean islands brought the clinics to the epicentre once again. However, when the first official camps began to appear, controversies arose within the clinics' network. The " 5 th annual conference of social solidarity clinics and pharmacies" in April 2016, is indicative of these internal debates (field notes, Thessaloniki, 2016). On the one hand, the clinic of Nea Philadelpheia argued, among others, that healthcare provision in closed camps opposes the clinics' principle on self-management, and thus it should be avoided; with the more radical ones, like the clinics of Volos and Ilion, withdrawing their participation from the network. On the other hand, clinics like those in Peristeri, SCK and Piraeus supported the clinics' cooperation with the state, NGOs, church organizations and any actor working on the provision of health services to refugees.

\subsection{Identity}

Although the variety of actors involved in the social movement scene of food complicates the analysis concerning collective identity, the social movement scene of health presents a simpler picture. Social clinics distinguished themselves from the institutional healthcare providers (SSCP MKIE, 2014e), setting in motion the mechanism of boundary activation (Tilly and Tarrow, 2015, p. 36). The distinction of one group (or set of actors) and the formation of its identity based on the differences with other actors, is a rather usual procedure that social movements undergo, and as such it does not explain much. Our interest in understanding and exposing the process of boundary 
enlargement leads us to identify how social clinics form their peculiar identity and how this identity is not solid and stable, but dynamic and liquid. In order to do this, we pay attention to the mechanisms of social appropriation and translation and their respective sub-mechanisms.

\subsubsection{Social Appropriation through Organization and Resources}

Earlier we underlined our intention to further foster the bridging of the structural and cultural approaches to social movements. Robnett argues that 'resources, political opportunities, and organizational strength are important determinants in creating a social movement culture that in turn creates collective identities' (2002, p. 268). In this sense, identity seems to act as the connective glue. In the case of social clinics this is better exposed with the mechanism of social appropriation and the sub-mechanisms of partial commitment and resource certification.

Social appropriation indicates the 'conversion or incorporation of previously existing non-political groups and networks into political actors' (Alimi et al., 2015, p. 287). With reference to the role of black churches during the civil rights movement in the USA, Tilly and Tarrow (2015, p. 36) argue that social appropriation mechanisms can be found in the organizational and institutional basis of the movement campaigns. This is also true in the case of social clinics, where their organizational structure has enabled the incorporation of previously non-political actors in their operation. The social appropriation mechanism marks the shift of movement from non-adherents into adherents, as described by resource mobilization theory (McCarthy and Zald, 1977, p. 1221). However, since social appropriation is related to a change in the individuals' identity from one state of being to another, we conceive the activation of this mechanism in relation to the clinics' identity. This is fueled by two additional sub-mechanisms. Since resource certification was described in detail in the previous section, it is worth providing some insight regarding the sub-mechanism of partial commitment. Tilly's popular definition of social movements holds commitment, meaning the 'persistence in costly or risky activity, declarations of readiness to persevere, resistance to attack', as one of the four basic characteristics (the other three being Worthiness, Unity and Number) (Tilly, 2003, p. 252). Although commitment is crucial for the sustenance of social movements and SMOs, Tilly's suggestion is quite ambitious as, in reality, the degree and intensity of the activists' engagement varies significantly. The absence of a mechanism with which to demonstrate this variation, as well as the opportunity provided by the alternative repertoires for minimizing the level of participation without 
a respective decrease of someone's role within the organization, led us to introduce the sub-mechanism of partial commitment.

Along with movement-like procedures, social clinics tend to have many similarities with proper institutional clinics in terms of their operation. To quote an interviewee from Peristeri,

I organized the clinic as I had organized my personal office. The patients' health cards were based on the procedure I followed in my office. [...] The process of keeping records was similar to the one followed by the hospital I was working earlier. The same organizational system I followed in my office and in the hospital has been applied and adjusted to the clinic. (Int.12)

This becomes evident with regards to the clinics' organizational structure and the shift-based model that they follow.

Unlike strictly political organizations, which require their members to be fully committed in terms of values and participation in the actions, social clinics introduced a relatively open model. Apart from the compliance with the broad values of the respective clinic $^{10}$, the members are free to choose the way, duration and intensity of their contribution. The clinics follow a shift-based operation, which in practical terms means that both specialized and non-specialized personnel devote their services based on a specific timetable. In this sense, the members' commitment to the organization is only partial. As many interviewees noted, a potential member can offer their services a couple of hours per week without it affecting their role, rights and responsibilities in the clinic (Int.16). This, in turn, is central to the characteristics of social movement scenes (Haunss and Leach, 2007; Leach and Haunss, 2009).

The open character of social clinics affects the overall participation, since it reduces the respective costs in time. Quite striking is the fact, however, that partial commitment applies also to the participation in the clinics' general assemblies. An interviewee from Thessaloniki recalls that, 'I joined the social clinic four years ago [...] without having any contact with the general assembly; without having any contact with the political part of the clinic' (Int.5). This points out that service provision, although theoretically supportive, is practically separate from the usual forms of political engagement. Non-participation becomes quite remarkable with

10 Among the healthcare providers set up by movement initiatives, NGOs, Church, municipal and professional associations, 27 have set specific criteria for potential members while 24 have not (Adam and Teloni, 2015, p. 65). 
regards to the two external networks, of which the members rarely take part in the clinics' general assemblies.

Multiple causes seem to have led to this result. Among others, the great workload of the members limits their free time (Int.6); the intensity and disputes between individuals with conflicting political views, especially after the electoral victory of SYRIZA, annoyed others and turned them solely to the provision of services (Int.5); while the members' ability to be updated on current issues and express their views electronically via the clinics' mailing list decreased the need for their physical attendance (Int.16). Reverse trends have also been observed: some members who first participated in the provision of services, later joined the general assemblies (Int.5). Additionally, clinics like Adye in Exarcheia are clear products of assembly-based procedures, recognizing that physical participation in the assemblies is of major importance. In the same vein, another interviewee informs us on the great attendance in assemblies which followed the election of SYRIZA in the governmental coalition in January 2015: 'I remember the first assembly after SYRIZA got elected, when there wasn't an empty chair to sit!' (Int.5). Similar to the square movement, this enthusiasm for participating in assemblies is often combined with high levels of mobilization and increased interest, when there is an important issue at stake, while it is rarely observed in silent periods when the assemblies' agendas deal with everyday issues. Nevertheless, the case of social clinics witnessed a broader lack of activists' enthusiasm in participating in assemblies, instead they kept seeking politicization through action. In the words of an interviewee, 'what keeps the clinic alive is its practical character. If we stayed only on a theoretical level, we would have disappeared in the very first year' (Int.16).

Scholars note that multiple identities inevitably lead to the construction of a hierarchical order, where identities are being classified according to their salience (Snow, 2013, p. 268). In respect to social clinics, the provision of services acquires substantial salience and is considered a form of political engagement in itself. This commitment to the provision of services has loosened the clinics' structures and enabled the engagement of people from a variety of political backgrounds. An interviewee from Thessaloniki informed us that,

both the founders and the first members of the clinic came from the Left. The anarchists left quite soon. With regards to the people in solidarity, however, the range is quite great. Some of them belong to the political Centre and engaged with the clinic quite actively. Probably, the most remarkable difference is that people in solidarity who participate in the secretary service or assist the pharmacy's operation, do not belong to the 
Left, radical Left or the anarchist space; while the ones who participate in the assemblies are mostly from the Left. (Int.6)

Another interviewee argued that apart from the Left,

the clinic has attracted people that just heard about it without any previous involvement in social movement activities. Despite our controversies, disagreements and conflicts, our common claim concerns the free universal access to the health system. [...] Once, a newcomer asked me "whether we provide treatment also to Roma people" and I freaked out. Nevertheless, in due time this person got engaged with the clinic and participated quite actively. (Int.16)

Similar xenophobic incidents were observed in other clinics, in particular after the summer of 2015, when social clinics dealt mostly with refugees and migrants and to a lesser extent with the domestic population. Nevertheless, in most cases these voices gradually turned down and changed, something that emphasizes the transformative dynamics that collective action has on individuals.

The non-participation in the assemblies bears the risk of a deeper democratic deficit and intensifies the quest for alternative paths of politicization. Partial commitment lowers activists' costs in terms of time spent in social movement activities. At the same time though, the attention of clinics to conventional rather than disruptive practices allow partial commitment to also reduce more generic risks and costs, such as police repression or exposure to threatening environments that participation in collective action carries. The sub-mechanism of partial commitment shows how an aspect of organization has strong repercussions for the factor of identity, since it hinders the development of internal confrontation and factionalism. However, the partial character of this commitment does not seem to affect its strength. Snow claims that the higher the role of an identity in the individual's hierarchy, the greater the commitment shown by the individual to this identity (Snow, 2013, p. 268). Following this point, the clinics' commitment to healthcare provision became more specialized. In particular, the group "other medicine" operating in Thessaloniki's social clinic, deployed its commitment to holistic approaches to medicine and self-management, which led to the establishment of the Workers' Medical Centre at Vio.Me.

The new clinic does not only question the meaning of property, since it operates in squatted premises, but most importantly it puts in question the foundations of health provision as we know it. In particular, the Workers' Medical 
Centre tries to change two fundamental aspects: first, who is the healthcare provider and second, what healthcare means. In this respect, the clinic rejects the traditional doctor-patient model, treats the patient as "incomer" and replaces the doctor with what is called the "medical team". The fifteen-member medical team is divided into small, three-member groups, which always consist of a general doctor-pathologist, a Psy member (meaning psychologist, psychotherapist or sociologist) and another member who can also be non-medical personnel. The clinic's holistic approach obliges its members to devote significant time to each incomer, whose personal health card does not contain only their medical background but also their psychological and occupational status. ${ }^{11}$

The sub-mechanism of partial commitment shows how an aspect of organization has strong repercussions for the factor of identity. In this respect, partial commitment manages to bridge structural and cultural issues. So does the mechanism of resource certification which underlines the interaction of clinics' resources with the factor of identity.

The analysis of the previous section aimed to shed some light on how the certification of the clinics' resources enabled the latter to develop links with previous unconnected sites of the social movement community. At the same time, donations played a double role: on the one hand, they helped to sustain the clinics' operation, and, on the other hand, facilitated the engagement of individuals with the clinics. Either directly or indirectly, potential donors have been equated with what Snow called the audience identity field (Ibid, pp. 274-275) and developed into the clinics' target population. The identity strategy (Taylor, 2013, p. 41) of the MKIE clinic aimed to bring individuals within its premises and transform them into its ambassadors. At the same time though, MKIE and other clinics also tried to engage their beneficiaries in the provision of services (Hadjimichalis, 2017, p. 165). Commenting on a bag of drugs left by a donor in the clinic's front-door when it was closed, an interviewee from Peristeri claimed that,

we tried to socialize our effort, to make it popular and this is the substantial respond. The people who visited the clinic understood that they should communicate its existence; that you can contact us, bring the medicine you don't need since someone else may need it. The great amount of people that contacted the clinic have realized that medicines are social goods and not commodities to be exploited by corporations; this is the most important success of our movement. [...] Both donors and beneficiaries have also started to participate in the clinic as volunteers. (Int.11)

11 For a detailed description on the novelty of the Workers' Medical Centre in the factory of Vio.Me see Carenotes (2020). 
Contrary to linear accounts, which would presume that protagonists affect the audience, identity factors are rather dynamic in the sense that clinics affect and are affected by their donors (Snow, 2013, pp. 274-275). Under this dialectic model, the collective identity of clinics is under continuous negotiation among the clinics' members, the donors, and of course its antagonists, who could be pictured here as the government and public institutions (Robnett, 2002, p. 268). In order to demonstrate this process of negotiation, we now turn to the mechanism of translation.

\subsubsection{Translation and Bricolage}

Dinerstein (2015) states that translation was the threat of deconstructing autonomous politics and creating hopelessness in Latin America. The author treats translation as the 'processes, mechanisms and dynamics through which autonomous organizing is integrated into the logic of power, and through which what does not fit into this demarcation is invisibilised or politically obliterated' (Ibid, pp. 69-70). In our context, we mean the way in which 'practices that travel from one site to another are modified and implemented by adopters in different ways so that they will blend into and fit the local social and institutional context' (Campbell, 2005, p. 55). Campbell introduces the notion of bricolage in order to refer to the 'innovative recombination of elements' which 'may entail the rearrangement of elements that are already at hand, but it may also entail the blending in of new elements that have diffused from elsewhere' (Ibid). As Campbell notes, both symbolic and technical elements render bricolage 'a new way of configuring organizations, social movements, institutions, and other forms of social activity' (Ibid). Bricolage occupies an important role in this debate (Campbell, 2005, pp. 53-54), as it demonstrates how the combination of symbolic and technical elements synthesize this mosaic. Campbell (2005) argues that translation and bricolage are vital characteristics of the diffusion mechanism, since they show how frames, approaches, and practices are diffused and adapted in new contexts (Ibid). In our context, however, they are treated as components of the clinics' identity factor.

The mechanism of translation occurred in facilitating the interaction between "theory" (participation in the assembly) and "action" (active provision of services). The combination of elements such as the individuals' will and social background, the duty, responsibility and personal effort in supporting the clinics' operation, as well as the distaste for langue de bois elevate the provision of services to the ultimate form of solidarity. In this respect, translation becomes the connective glue between partial commitment and organizational structure, by turning political participation into service provision. 
Similarly, translation interacts with the factor of resources and the clinics' internal controversies. Their operation in places granted by municipal authorities does not seem to create noteworthy problems to the clinics in terms of independence, nor does it inhibit collaboration with SMOs or institutional actors. The denouncement of austerity policies and the clinics' refusal to be incorporated within the state's structures have been used as counterweights to balance those blurred relations. From a strictly ideological perspective, these controversies imply that practices such as direct democracy, self-management, autonomy and others have been misunderstood. Changes in the (attribution of) political opportunity structure with the arrival of SYRIZA provoked disputes along these frames, led to the isolation of some clinics from their network and affected the cohesiveness of the movement (Benford 1993: 694-697 in Staggenborg, 2011, p. 21). However, this explanation seems partial if we do not take into account the overall process of boundary enlargement and the nodal role that translation acquires.

Direct-democratic practices, autonomy and self-management made up a considerable proportion of anarchist, libertarian and radical left-wing organizations' agendas. However, the square movement put an end to this tradition of isolation, diffusing them into parts of the wider population, including also a number of first-time protesters. As Cabot (2016, p. 158) notes, 'austerity and crisis in Greece have, indeed, reconfigured the boundaries of social and political communities'. The subsequent decentralization of the square movement brought these values on a local level, with the clinics continuing this legacy. 'It is relatively easier to maintain your political purity in Exarcheia but not in Nea Philadelphia. The political level is different both in terms of the volunteers and the beneficiaries' (Int.14), argued one interviewee. In these terms, translation is contextualized and depends on the spatial/urban political culture. Moreover, a heated debate resulted in the withdrawal of the anti-authoritarian fraction from Thessaloniki's social clinic, following the disclosure that one of the clinic's members was a former police officer. The issue sparked again two years later with some members accusing the policeman for disturbing the clinic's operation and asking her to leave. As an interviewee explained, 'together with her, however, other members left the clinic, questioning its open character and "whether we all fit here or not" arguing that it was an issue of internal democracy' (Int.6).

Having members that are former policemen would be out of the question probably for all the traditional SMOs a few years ago. In the personal conversation with an activist that is also a member of Adye clinic, the potential police infiltration was underlined as the risk of introducing open 
structures (Int.15). However, in the case of Thessaloniki clinic, the members knew about the former occupation of its member. This particular case spurred debate and opened a broader discussion on the "open structure" of SMOs. Adye differs from the vast majority of the social clinics in its clear political (and ideological) orientation. On the contrary, most of the interviewees have emphasized the political heterogeneity of the clinics, which inevitably leads to a process of continuous negotiation regarding their identity. In some cases, this process reserved surprises.

Our members come from various political backgrounds. Recently I was surprised by the news that one volunteer comes from the extreme right. We have chosen to be open, and despite the anti-racist profile, we don't have any exclusion criteria. We believe that the clinic should be representative of what is going on in the society. (Int.7)

Based on the aforementioned quote, the clinic in Thermi presents a clear case where identity is a direct product of political and ideological bricolage. Although field research shows that a few clinics have also experienced similar incidents, this is the exception rather than the rule. In a number of cases, members or beneficiaries expressing discriminatory claims are directly ousted. Nevertheless, these examples display how internal processes affect the construction of the clinics' collective identity.

According to Taylor, boundaries, negotiation and consciousness over the criteria 'that explain a group's structural position and common interests' (2013, p. 39) make up the underpinnings of collective identity. The previous examples were quite indicative in showing the amalgam of political positions through bricolage. However, these characteristics should not be studied in isolation; it is through their combination and subsequent interplay with social life and everyday practices that enable the formation of collective identity (Melucci, 2002). In this respect, the daily confrontation with hardships and human suffering complement the clinics' distinct identity. Social clinics served as caldrons, where veteran activists, eminent doctors, middle-class citizens and beneficiaries from different social and political backgrounds blend their individual identities, put aside the status designated by their respective expertise and decide altogether on an equal base.

The open character of social clinics has resulted in a mixture of different identities. McAdam et al. (2009) argue that interaction between different actors does not reproduce their previous relations but has transformative dynamics both to the actors and their relations. In this respect, the submechanism of bricolage has also affected precisely the subject of social 
clinics, namely the provision of healthcare. Speaking about the clinic's external networks, an interviewee from Thessaloniki notes that,

roles are changing with doctors becoming brokers. By using their contacts to facilitate the admission of a beneficiary in a public hospital, doctors transform themselves into social workers. This would happen neither in a regular clinic, where the secretary would not take the responsibility; nor in the clinics run by NGOs, where beneficiaries are confronted with skepticism and face-control for whether they fit the required criteria. We also call the beneficiaries to actively participate in our actions. Some turned into protesters, others become members and many of them try to "pay us back", to create a relationship. This was for example the case when a beneficiary volunteered to paint the clinic. (Int.5)

In his discussion about movement outcomes, Tarrow (1998, pp. 166-167) suggests that the nature of participation in collective action is a means of politicization. As the author goes on to suggest, this politicization can be highly empowering for the participants. Nonetheless, empowerment here is not treated as an outcome, but rather as a process that leads to the activists and beneficiaries' further engagement. From this view, another interviewee added that,

social clinics didn't restrict their roles in philanthropy by providing top-down health services, but moved towards solidarity and established relations with the beneficiaries. The dynamic character of this relationship does not exist in the regular hospitals. When someone gets sick, we don't simply provide medicine, we treat the patient holistically. Most importantly, patients are treated with compassion; the loss of employment humiliates them, makes them feel useless and they usually enter the clinic with their heads down. Here they are treated with respect; they are treated as equal to equal and they understand that their value as humans is much more substantial than their occupational status. This is also reflected in their complaints for losing this warm atmosphere now that the healthcare system has opened (access also for unemployed). (Int. 8)

\subsection{Conclusion}

This chapter aims to uncover the development of the boundary enlargement process regarding the social movement scene of health. Table 4.1 
Table 4.1 Mechanisms and sub-mechanisms in the social movement scene of Health

\begin{tabular}{lll}
\hline & Mechanisms & Sub-mechanisms \\
\hline $\begin{array}{l}\text { Organizational } \\
\text { Structure }\end{array}$ & In-group Brokerage & $\begin{array}{l}\text { Network Cultivation + Attribution of } \\
\text { Similarity }\end{array}$ \\
\hline Resources & $\begin{array}{l}\text { Out-group Brokerage } \\
\text { Diffusion }\end{array}$ & $\begin{array}{l}\text { Resource Certification } \\
\text { Emulation + In-group Brokerage }\end{array}$ \\
\hline Identity & Social Appropriation & Partial Commitment + Resource Certification \\
& Translation & Bricolage \\
\hline
\end{tabular}

demonstrates the basic mechanisms and sub-mechanisms which compose this process.

In order to understand the mechanisms that constitute the boundary enlargement process in terms of the organizational structure of social clinics, we tried to emphasize the role of the operational and political axes. In line with their independent character, the clinics are organized based on an affinity groups modeling. Among other factors, such as ideology or eventful protests that facilitate the establishment of connections among these groups, the case of social clinics supports that the translation of common goals into repertoires of action might also be significant for activating the mechanism of in-group brokerage. This entails connecting a number of healthcare professionals and people in solidarity with the clinics' operation. The further deconstruction of the in-group brokerage mechanism reveals the sub-mechanisms of attribution of similarity and network cultivation.

The exploration of these sub-mechanisms proceeds respectively with the decomposition of the clinics' organizational structure. Aspects such as the general assembly and coordinating committees, as well as the different working groups operating within the clinics, shed light on how the attribution of similarities lead to the cultivation of the clinics' networks. This becomes quite clear when we analyse the core and peripheral networks of the clinics. Here, we distinguish two important aspects. First, the role of the doctors' professional networks for establishing connections within and among the clinics based on their professional networks; and second, the reflection of the beneficiaries' exclusion from the public health system as a potential reality for the non-specialized personnel. Doctors working in private clinics and public hospitals agreed to provide their services to the clinics once they saw their colleagues already doing so. Respectively, the fear of becoming a potential patient was crucial for engaging a number of people in solidarity with the clinics' operation. Of course, we do not want to undermine other factors that contributed to their engagement, nor to re-invent the wheel. Profession was 
the basic connective element in the labour movement and trade unions, while the attribution of threat has been long analysed in social movement literature as a mobilizing factor. Nevertheless, in times when austerity policies deny access to almost 3 million of citizens to the health system, these proved to be rather decisive elements for fostering participation in collective action.

These accounts would be incomplete without considering the political axe of the clinics. The diffusion of direct democracy, mutual respect and horizontal decision-making from the square movement and previous phases of mobilization were factors that enabled a minimum political agreement among the clinics' members and imposed the conditions for the cultivation of their networks. Overall, the clinics' organizational structures provide empirical accounts on how, among other mechanisms, the attribution of similarities enabled the cultivation of the social clinics' networks, which subsequently set in motion the connection of previously unconnected sites.

Turning our attention to the social movement scene of health, this research argues that, among other differences between the movements of affluence and those of crisis, the material needs created under the latter's external conditions decrease the requirements for the establishment of SMOs as well as the construction of networks and alliances. This is both an important outcome and a condition of the process of boundary enlargement. Our elaboration on the clinics' resources brought aspects of past theories to the forefront, demonstrating some important innovations and revealing a number of contradictions. Most importantly, we tried to show how resources are connective elements between the clinics and previously unconnected sites. In the jargon of contentious politics, resource certification operates as a sub-mechanism which is critical to the construction of the out-group brokerage mechanism. This is better understood in the case of medication.

Medicine's relatively low cost, its utility in covering basic needs, the transparent character of donations in kind, combined with the rhetoric that 'austerity systematically kills the health system' (SSCP MKIE, 2014d), inspired individuals and collectives to affiliate with the clinics through the collection and donation of medicine. Resource certification has activated the out-group brokerage mechanism which connected the clinics with other SMOs. However, the internal debates expressed in the clinics' national conference in 2016 demonstrate that the same sub-mechanism has triggered internal rivalries, deconstructed their alliances and de-legitimized some clinics in the eyes of others when certification came by institutional actors who were in power.

If we isolate these findings, the results are inconclusive. If we combine them, however, with the mechanisms identified in the factors of organizational structure and identity, resources become important connective (and 
disjunctive) elements not only among organizations, but also between the material infrastructure and the post-material views.

David Meyer argues that 'the process of turning physical features or social practices into "identities" is forged by the interaction between people and the state' (2002, p. 5). In our effort to shed light to the identity factor of social clinics, we occupy a dynamic, post-structural approach, arguing that collective identities are shaped both by the external conditions and austerity policies on health and by the internal processes and agency developed within the social clinics. The process of boundary enlargement was predominantly influenced by the combination of two sub-mechanisms discussed here: our focus on the clinics' organizational structure and resources revealed how the respective sub-mechanisms of partial commitment and resource certification facilitate the mechanism of social appropriation. In other words, the low cost of participation in the clinics, together with the approval of the latter's services through medicine donations, were essential for engaging a number of volunteers in the clinics. The loose character of the structures and the intermediate role of resources enabled the further engagement of the broader audience with the clinics' operation.

Nevertheless, this would not be enough to explain the clinics' identity, without taking into consideration the way in which political participation is translated into the provision of services. In accordance with the related literature, social clinics (or fractions within them) with clear identities have proceeded to sharp distinctions and conflicts. However, the ones 'whose identities are relatively diffuse or fluid are better placed to play the brokerage roles by which movements may be held together' (Rootes, 2013, p. 307). The sub-mechanism of bricolage was crucial in explaining this role. More precisely, bricolage allowed us to identify how practices, norms and values have been translated and adapted in different contexts and how a number of elements have been combined, resulting in the peculiar character of the social clinics' identity.

\section{Bibliograhpy}

Adam, S., \& Teloni, D.-D. (2015). Solidarity Clinics in Crisis-Ridden Greece: The Experience of Health Care Provision When Public Health Care Is in Retreat [Kolvwvixá

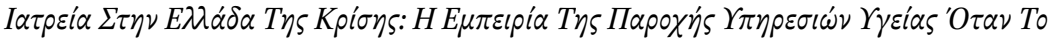

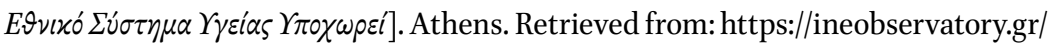
publication/kinonika-iatria-stin-ellada-tis-krisis-i-empiria-tis-parochis-ipiresionigias-otan-to-ethniko-sistima-igias-ipochori/ Last Accessed: 28 April 2020 
Alimi, E. Y., Bosi, L., \& Demetriou, C. (2015). The Dynamics of Radicalization: A Relational and Comparative Perspective. New York: Oxford University Press.

Cabot, H. (2016). 'Contagious' Solidarity: Reconfiguring Care and Citizenship in Greece's Social Clinics. Social Anthropology, 24(2), 152-166.

Campbell, J. L. (2005). Where Do We Stand? Common Mechanisms in Organizations and Social Movement Research. In D. McAdam, G. F. Davis, M. N. Zald, \& W. R. Scott (Eds.), Social Movements and Organization Theory (pp. 41-68). Cambridge: Cambridge University Press.

Carenotes (Ed.) (2020). For Health Autonomy: Horizons of Care Beyond Austerity Reflections from Greece. New York: Common Notions.

Clemens, E. S. (2005). Two Kinds of Stuff: The Current Encounter of Social Movements and Organizations. In D. McAdam, G. F. Davis, M. N. Zald, \& W. R. Scott (Eds.), Social Movements and Organization Theory (pp. 351-366). Cambridge: Cambridge University Press.

Davis, G. F., McAdam, D., Scott, W. R., \& Zald, M. N. (2005). Social Movements and Organization Theory. New York: Cambridge University Press.

Della Porta, D. (2008). Eventful Protest, Global Conflicts. Distinktion: Scandinavian Journal of Social Theory, 9(2), 27-56.

Della Porta, D. (2015). Social Movements in Times of Austerity: Bringing Capitalism Back into Protest Analysis. Cambridge: Polity.

Della Porta, D., Andretta, M., Fernandes, T., Romanos, E., \& Vogiatzoglou, M. (2018). Legacies and Memories in Movements:Justice and Democracy in Southern Europe. New York: Oxford University Press.

Della Porta, D., Andretta, M., \& Mosca, L. (2006). Globalization from Below: Transnational Activists and Protest Networks. Minneapolis: University of Minnesota Press,.

Diani, M. (2015). The Cement of Civil Society. Cambridge: Cambridge University Press.

Diani, M., \& Mische, A. (2015). Network Approaches and Social Movements. In D. Dela Porta \& M. Diani (Eds.), The Oxford Handbook of Social Movements (pp. 306-325). New York: Oxford.

Dinerstein, A. C. (2015). The Politics of Autonomy in Latin America: The Art of Organising Hope. Hampsire: Palgrave Macmillan.

Goodwin, J., \& Jasper, J. M. (Eds.). (2015). The Social Movements Reader: Cases and Concepts. Chichester: Wiley-Blackwell.

Hadjimichalis, C. (2017). Crisis Spaces: Structures, Struggles and Solidarity in Southern Europe. New York: Routledge.

Haunss, S., \& Leach, D. K. (2007). Social Movement Scenes: Infrastructures of Opposition in Civil Society. In D. Purdue (Ed.), Civil Societies and Social Movements (pp. 85-101). Oxon: Routledge/ECPR Studies in European Political Science. 
Jasper, J., \& Poulsen, J. (1995). Recruiting Strangers and Friends: Moral Shocks and Social Networks in Animal Rights and Anti-Nuclear Protests. Social Problems, 42(4), 493-512. doi:10.2307/3097043

Kotronaki, L. (2015). The Theory of Contentious Politics in the Practice of Social Movements: The Movement against the Neoliberal Globalization (Greece, 2000-20o6)

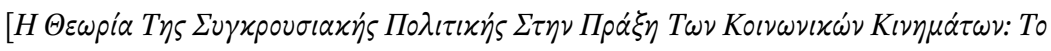

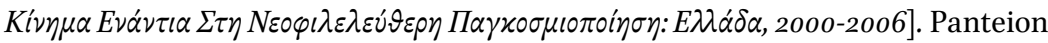
University of Social and Political Sciences. Retrieved from: https://www.didaktorika.gr/eadd/handle/10442/37556 Last Accessed: 28 April 2020

Leach, D. K., \& Haunss, S. (2009). Scenes and Social Movements. In H. Johnston (Ed.), Culture, Social Movements, and Protest. Farnham: Ashgate Publishing,Ltd. McAdam, D., Tarrow, S. G., \& Tilly, C. (2001). Dynamics of Contention. Cambridge, U.K.; New York: Cambridge University Press.

McAdam, D., Tarrow, S., \& Tilly, C. (2009). Comparative Perspectives on Contentious Politics. In M. I. Lichbach \& A. S. Zuckerman (Eds.), Comparative Politics: Rationality, Culture, and Structure (pp. 260-290). New York: Cambridge University Press.

McCarthy, J. D., \& Zald, M. N. (1977). Resource Mobilization and Social Movements: A Partial Theory. American Journal of Sociology, 82(6), 1212-1241. doi:10.1086/226464

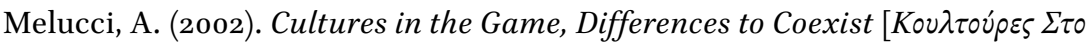

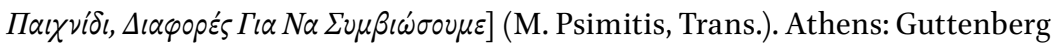

Meyer, D. S. (2002). Opportunities and Identities: Bridge-Building in the Study of Social Movements. In D. S. Meyer, N. Whittier, \& B. Robnett (Eds.), Social Movements: Identity, Culture, and the State (pp. 3-24). Oxford; New York: Oxford University Press.

Robnett, B. (2002). External Political Change, Collective Identities, and Participation in Social Movement Organizations. In Social Movements: Identity, Culture, and the State (pp. 266-285). New York: Oxford.

Rootes, C. (2013). Discussion: Mobilization and the Changing and Persistent Dynamics of Political Participation. In J. v. Stekelenburg, C. Roggeband, \& B. Klandermans (Eds.), The Future of Social Movement Research Dynamics, Mechanisms, and Processes (pp. 299-311). Minneapolis: University of Minnesota Press.

Snow, D. (2013). Identity Dilemmas, Discursive Fields, Identity Work, and Mobilization: Clarifying the Identity-Movement Nexus. In J. v. Stekelenburg, C. Roggeband, \& B. Klandermans (Eds.), The Future of Social Movement Research: Dynamics, Mechanisms, and Processes (pp. 263-280). Minneapolis: University of Minnesota Press.

Staggenborg, S. (2011). Social Movements (Rev. ed.). New York: Oxford University Press. 
Tarrow, S. (1998). Power in Movement: Social Movements and Contentious Politics (2nd ed ed.). Cambridge: Cambridge University Press.

Taylor, V. (2013). Social Movement Participation in the Global Society: Identity, Networks and Emotions. In J. v. Stekelenburg, C. Roggeband, \& B. Klandermans (Eds.), The Future of Social Movement Research: Dynamics, Mechanisms, and Processes (pp. 37-57). Minneapolis: University of Minnesota Press.

Tilly, C. (2003). Agendas for Students of Social Movements. In J. Goldstone (Ed.), States, Parties, and Social Movements (pp. 246-256). Cambridge: Cambridge University Press.

Tilly, C., \& Tarrow, S. G. (2015). Contentious Politics (Second revised edition. ed.). New York, NY: Oxford University Press.

Wang, D., Piazza, A., \& Soule, S. A. (2018). Boundary-Spanning in Social Movements: Antecedents and Outcomes. Annual Review of Sociology, 44, 167-187.

\section{SMO Material}

CI Thermi. (2013, January 4). 'Citizen Committee of Thermi, Assembly in 16/1/2013'.

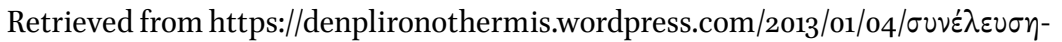

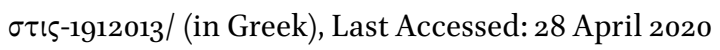

Litsis M. and Stefanakos S. [Vmedia.gr]. (2014, May 6). We walk together, 6/5/2014. [video file]. Retrieved from https://www.youtube.com/watch?v=D2EcpiGLgZE (in Greek), Last Accessed: 28 April 2020

[Omniatv]. (2014, October 22). Without Backup. MKIE: Solidarity in practice. [video file]. Retrieved from https://vimeo.com/109751847 (in Greek), Last Accessed: 28 April 2020

[SSCP MKIE]. (2013, January 9). English Language Presentation of MKIE [video file]. Retrieved from https://www.youtube.com/watch?time continue $=123 \& v=\mathrm{k} 7 \mathrm{hTgTiA} 4 \mathrm{jA}$,Last Accessed: 28 April 2020

SSCP MKIE. (2012c, August 12). 'Press Release: Initiative for specialized medical equipment and drugs in public hospitals'. Retrieved from http://www. mkiellinikou.org/en/2012/o8/o8/press-release-initiative-for-specializedmedicalequipment-and-drugs-in-public-hospitals/, Last Accessed: 28 April 2020 SSCP MKIE. (2014d, July 18). 'Finally Stop your Cruel Policies'. Retrieved from http:// www.mkiellinikou.org/blog/2014/07/18/politikes/ (in Greek), Last Accessed: 28 April 2020

SSCP MKIE. (2014e, June 23). 'The social Trojan horse is here'. Retrieved from http://www.mkiellinikou.org/blog/2014/o6/23/ippos/ (in Greek), Last Accessed: 28 April 2020 
SSCP MKIE. (2014e, June 23). 'The social Trojan horse is here'. Retrieved from http://www.mkiellinikou.org/blog/2014/o6/23/ippos/ (in Greek), Last Accessed: 28 April 2020

SSCP MKIE. (2012c, August 12). 'Press Release: Initiative for specialized medical equipment and drugs in public hospitals'. Retrieved from http://www.mkiellinikou.org/en/2012/o8/o8/press-release-initiative-for-specialized-medicalequipment-and-drugs-in-public-hospitals/, Last Accessed: 28 April 2020

SSCP Nea Philadelphia. (n.d.). 'What is the Self-managed Social Clinic/Pharmacy of Nea Philadelphia'. Retrieved from https://koinonikoiatreionfnx.espivblogs. net/english/, Last Accessed: 28 April 2020

SSCP Thessaloniki. (2014c, September 19). 'It is not possible to be doctor and fascist'. Retrieved from http://www.kiathess.gr/gr/yliko/arthra/9o-fasistesgiatroi19o92014 (in Greek), Last Accessed: 28 April 2020

SSCP Thessaloniki. (2015, October 7). 'The Solidarity Social Medical Center in Thessaloniki'. Retrieved from http://www.kiathess.gr/en/about-us/structureoperation, Last Accessed: 28 April 2020

\section{List of Interviewees}

Interviewee 1 - Female, 51-55 years old, Doctor, Founding member of the social clinic in Rethimno, Crete (2.6.16) - Audio recorded - Transcribed in Greek

Interviewee 2 - Female, 41-45 years old, Doctor, Founding member of the social clinic in Rethimno, Crete (3.6.16) - Audio recorded - Transcribed in Greek

Interviewee 3 - Female, 46-50 years old, Dentist, Founding member Workers' Medical Centre at Vio.Me factory, Member of the social clinic in Thessaloniki (10.10.16) - Audio recorded - Transcribed in Greek

Interviewee 4 - Female, 46-50 years old, Public employee, Member of the social clinic in Thessaloniki (24.6.16) - Audio recorded - Transcribed in Greek

Interviewee 5 - Female, 31-35 years old, Social worker, Member of the social clinic in Thessaloniki, Member of Workers' Medical Centre at Vio.Me (26.5.16) - Audio recorded - Transcribed in Greek

Interviewee 6 - Female, 36-40 years old, Doctor, Member of the social clinic in Thessaloniki, Member of Workers' Medical Centre at Vio.Me (24.5.16) - Audio recorded - Transcribed in Greek

Interviewee 7 - Male, 51-55 years old, Freelancer, Founding Member of the social clinic in Thermi, Thessaloniki (1.7.16) - Audio recorded - Transcribed in Greek

Interviewee 8 - Male, 61-65 years old, Pensioner, Member of the social clinic in MKIE, Athens - Informal (16.11.16)- Audio recorded - Transcribed in Greek 
Interviewee 9- Male, 61-65 years old, Doctor, Founding member of the social clinic in Piraeus, Member of Solidarity Clinic of Koridalos, Athens (11.11.16) - Hand written notes - Transcribed in Greek

Interviewee 10 - Female, 56-6o years old, Pensioner, Founding Member of the social clinic in Athens (21.11.16) - Audio recorded - Transcribed in Greek

Interviewee 11- Female, 46-50 years old, Private employee, Member of the social clinic in Peristeri, Athens (19.11.16) - Audio recorded - Transcribed in Greek Interviewee 12 - Female, $5^{1-5}$ years old, Doctor, Founding Member of the social clinic in Peristeri, Athens (19.11.16) - Audio recorded - Transcribed in Greek Interviewee 14 - Female, 51-55 years old, Psychotherapist, Member of the social clinic in Nea Philadelphia, Athens (17.11.16) - Informal - Audio recorded - Transcribed in Greek

Interviewee 15 - Male, 36-40 years old, Sociologist, Founding member of ADYE social clinic, Athens - Informal - Personal Opinion Only (1.12.16) - Hand written notes -Transcribed in Greek

Interviewee 16 - Female, 41-45 years old, Dentist, Member of the social clinic in Thessaloniki (24.6.16) - Audio recorded - Transcribed in Greek 